\title{
DFT studies on tautomeric preferences of 1-(pyridin-2-yl)- 4-(quinolin-2-yl)butane-2,3-dione in the gas phase and in solution
}

\author{
Robert Dobosz $\cdot$ Ryszard Gawinecki • \\ Borys Ośmiałowski
}

Received: 31 August 2010/Accepted: 18 October 2010/Published online: 9 November 2010

(c) The Author(s) 2010. This article is published with open access at Springerlink.com

\begin{abstract}
Density functional theory (DFT) calculations show that in vacuum such $\alpha$-diketone as 1-(pyridin-2-yl)-4(quinolin-2-yl)butane-2,3-dione is much less stable than its enolimine-enaminone ((1Z,3Z)-3-hydroxy-4-(pyridin-2-yl)1-(quinolin-2(1H)-ylidene)but-3-en-2-one) and dienaminone tautomers ((1Z,3Z)-1-(pyridin-2-yl)-4-(quinolin-2-yl) buta-1,3-diene-2,3-diol). Other its tautomers (multiple basic and acidic centers in their molecules enable multiple proton transfer to take place) are even more labile. Strength of the intramolecular hydrogen bonds and aromatic character of the (quasi)rings [proved by the Harmonic Oscillator Model of Aromaticity (HOMA) index] in their molecules were found to be responsible for the observed tautomeric preferences. Polar and basic solvent disfavors and favors the enolimine and enaminone tautomers, respectively.
\end{abstract}

Keywords $\alpha$-Diketones - DFT calculations .

Tautomerism - Intramolecular hydrogen bond .

Solvent effect

\section{Introduction}

To an understanding of the reactions of a potentially tautomeric compound it is fundamental to know which

Electronic supplementary material The online version of this article (doi:10.1007/s11224-010-9674-y) contains supplementary material, which is available to authorized users.

R. Dobosz · R. Gawinecki $(\bowtie) \cdot$ B. Ośmiałowski

Department of Chemistry, University of Technology and Life

Sciences, Seminaryjna 3, 85-326 Bydgoszcz, Poland

e-mail: gawiner@utp.edu.pl tautomeric form predominates, and further to have information on the degree of predominance or energy difference involved [1]. In literature there are many examples of wrongly recognized tautomeric forms. Thus, in chloroform solution 2-phenacylquinoline is in tautomeric equilibrium with (Z)-1,2-dihydro-2-(benzoylmethylene)quinoline [2], misnamed earlier as (Z)-2-(2-hydroxy-2-phenylvinyl) quinoline [3]. Similarly, in DMSO solution 1-(p-methylphenacyl)isoquinoline equilibrates not with (Z)-1(2-hydroxy-2-(p-methylphenylvinyl)isoquinoline [4] but with (Z)-1,2-dihydro-1-( $p$-methylbenzoylmethylene)isoquinoline [5].

Some heterocyclic $\alpha$-diketones can be transformed into numerous tautomeric forms but only some of them have a chance to be present in the tautomeric mixture. NMR (chloroform solution), X-ray (crystal) and ab initio studies (vacuum and chloroform solution) show that (1Z,3Z)-1,4di(pyridin-2-yl)but-1,3-diene-2,3-diol and (3Z)-3-hydroxy1,4-di(quinolin-2-yl)-but-3-en-2-one are always more stable tautomeric forms than 1,4-di(pyridin-2-yl)butane2,3-dione and 1,4-di(quinolin-2-yl)butane-2,3-dione molecule, respectively [6, 7]. 1-(Pyridin-2-yl)-4-(quinolin-2-yl) butane-2,3-dione, the relative unsymmetrical $\alpha$-diketone, is not known but its susceptibility to the prototropic rearrangement seems also very interesting. The density functional theory (DFT) method used by us recently [8, 9] seems worthy to be applied to evaluate stabilities of this compound and its tautomers.

\section{Theoretical approach}

Standard B3LYP DFT calculations were carried out using Gaussian software package [10]. The B3LYP approach includes Becke's three parameter non-local hybrid 
exchange potential [11] and the non-local correlation functional of Lee et al. [12]. The 6-31+G(d,p) basis set with polarization functions on all atoms and diffuse functions on heavy atoms was used. Computations were performed for the isolated molecules (no intermolecular interactions were considered) and in the chloroform and DMSO solutions (using polarized continuum model PCM $[13,14])$. The vibrational frequencies were obtained at the same level to make sure that geometry is in minimum (no imaginary frequencies).

\section{Results and discussion}

There are multiple basic (two nitrogen and two oxygen atoms) and acidic (four methylene hydrogen atoms) centers in the molecule of 1-(pyridin-2-yl)-4-(quinolin-2-yl) butane-2,3-dione. As a consequence, this diketone may equilibrate with its numerous tautomers. Their formulas as well as numbering of heavy atoms in the molecule can be seen in Scheme 1. Except some exceptionally unstable rotamers [6,7], other species of this type are also included there.

All tautomers and rotamers shown in Scheme 1 were subjected to the DFT calculations. Comparison of their energies (Table 1) shows that only OEa and OOa are expected to be present in the tautomeric mixture in vacuum. These results are in agreement with our earlier studies that show that the respective dienol and enol/ enaminone forms are more stable than 1,4-bis(pyridin-2yl)butane-2,3-dione and 1,4-bis(quinolin-2-yl)butane-2,3dione, respectively $[6,7]$. Solvent, especially this more polar and of more basic properties (DMSO) disfavors the enolimine tautomers. Thus, OOa is present in vacuum only (Table 1). Moreover, contribution of OEa is highest in vacuum and lowest in DMSO. On the other hand, enaminone tautomers are favored in this solvent. Amount of EEa in chloroform and DMSO solutions is equal to 40 and $84 \%$, respectively. Some solute-solvent interactions of the hydrogen bond character are probably responsible for increased contribution of this tautomer. The calculated dipole moments of the respective tautomers/rotamers (Table 1) are not simply related to their relative proportions.

Relatively high contribution of the dienol tautomer OOa (Table 1) enables intramolecular proton transfer in OEa to take place (Scheme 2). Such tautomeric equilibria are not unique [7]. Calculations show that in vacuum the energies of 14.76 and $18.52 \mathrm{~kJ} / \mathrm{mol}$ are required for OEa to be transformed into OOa and EEa, respectively.

Contrary to their diketone tautomer, KKa, (1Z,3Z)-3hydroxy-4-(pyridin-2-yl)-1-(quinolin-2(1H)-ylidene)but-3en-2-one, OEa, and (1Z,3Z)-1-(pyridin-2-yl)-4-(quinolin2-yl)buta-1,3-diene-2,3-diol, OOa, are stabilized by the
Scheme 1 Tautomers and rotamers of 1-(pyridin-2-yl)-4(quinolin-2-yl)butane-2,3-dione ( $K$ ketone, $E$ enaminone, $O$ enolimine)
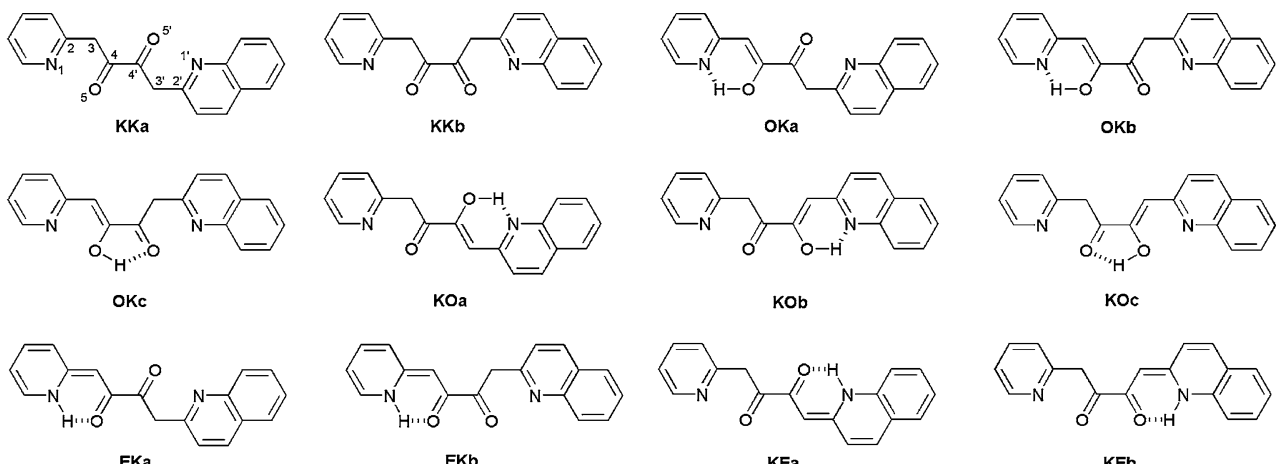

EKa

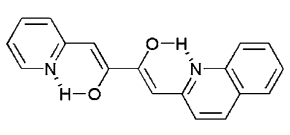

OOa

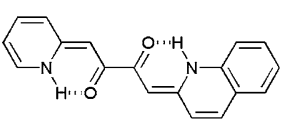

EEa

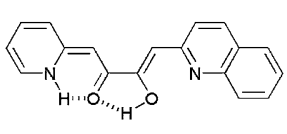

EOC

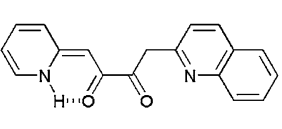

EKb

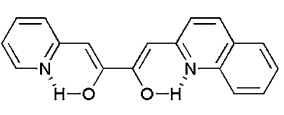

oob

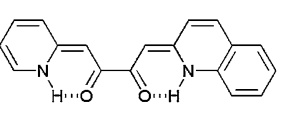

EEb

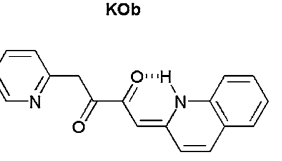

KEa

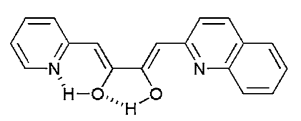

ooc

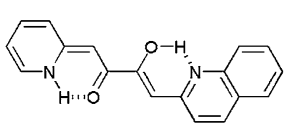

EOa

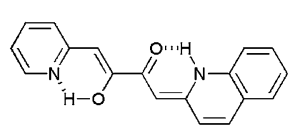

OEa

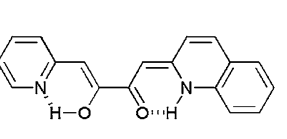

OEb

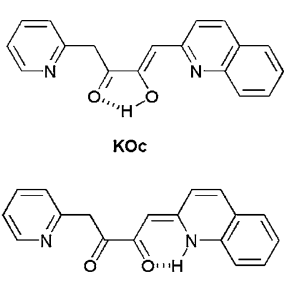

KEb

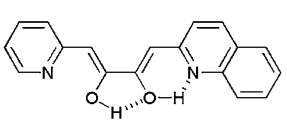

ood

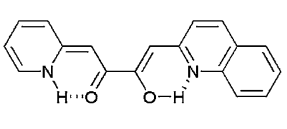

EOb

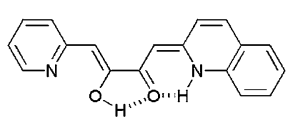

OEC 
Table 1 Relative energies (kJ/mol) of 1-(pyridin-2-yl)-4-(quinolin-2-yl)butane-2,3-dione and its tautomers/rotamers calculated at the B3LYP/6$31+\mathrm{G}(\mathrm{d}, \mathrm{p})$ level of theory

\begin{tabular}{|c|c|c|c|c|c|c|c|c|}
\hline \multicolumn{3}{|l|}{ Vacuum $^{\mathrm{a}}$} & \multicolumn{3}{|c|}{ Chloroform $^{\mathrm{a}}(\mu=1.08 \mathrm{D})^{\mathrm{b}}$} & \multicolumn{3}{|c|}{$\operatorname{DMSO}^{\mathrm{a}}(\mu=3.96 \mathrm{D})^{\mathrm{b}}$} \\
\hline $\begin{array}{l}\text { Tautomer/ } \\
\text { Rotamer }\end{array}$ & $\mu(\mathrm{D})^{\mathrm{c}}$ & $E_{\text {rel }}(\mathrm{P})^{\mathrm{d}}$ & $\begin{array}{l}\text { Tautomer/ } \\
\text { Rotamer }\end{array}$ & $\mu(\mathrm{D})^{\mathrm{c}}$ & $E_{\text {rel }}(\mathrm{P})^{\mathrm{d}}$ & $\begin{array}{l}\text { Tautomer/ } \\
\text { Rotamer }\end{array}$ & $\mu(\mathrm{D})^{\mathrm{c}}$ & $E_{\text {rel }}(\mathrm{P})^{\mathrm{d}}$ \\
\hline OEa & 1.22 & $0.00^{\mathrm{e}}(74.6 \%)$ & OEa & 2.04 & $0.00^{\mathrm{f}}(58.3 \%)$ & EEa & 0.70 & $0.00^{\mathrm{g}}(84.2 \%)$ \\
\hline OOa & 0.27 & $2.50(24.7 \%)$ & EEa & 0.69 & $0.84(40.1 \%)$ & OEa & 2.45 & $4.21(13.2 \%)$ \\
\hline EEa & 0.57 & 11.29 & OOa & 0.29 & 10.02 & EEb & 8.48 & 8.55 \\
\hline EOa & 1.97 & 13.86 & EOa & 2.94 & 10.25 & EOa & 3.37 & 12.49 \\
\hline OEb & 4.75 & 21.29 & OEb & 6.91 & 13.69 & OEb & 8.14 & 13.02 \\
\hline OOb & 4.22 & 24.25 & EEb & 7.02 & 15.22 & KEa & 7.70 & 16.62 \\
\hline KEa & 4.93 & 24.52 & KEa & 6.79 & 16.22 & OOa & 0.28 & 17.36 \\
\hline KOa & 3.69 & 29.25 & EOb & 7.04 & 23.99 & EOb & 8.33 & 21.85 \\
\hline OKa & 4.31 & 34.46 & OOb & 5.97 & 25.79 & KEb & 10.90 & 26.10 \\
\hline EOb & 4.79 & 35.02 & KOa & 4.97 & 27.58 & OEc & 10.05 & 28.54 \\
\hline EEb & 4.65 & 35.98 & OEc & 8.89 & 29.59 & OOb & 6.99 & 29.36 \\
\hline OEc & 6.47 & 37.85 & KEb & 9.10 & 31.72 & EKa & 9.77 & 30.65 \\
\hline KOb & 5.26 & 39.46 & EKa & 8.57 & 32.20 & KOa & 5.49 & 31.03 \\
\hline EKa & 6.02 & 42.95 & OKa & 6.28 & 33.26 & OKa & 6.68 & 36.82 \\
\hline KEb & 6.07 & 50.05 & KOb & 7.42 & 36.20 & EKb & 14.49 & 38.80 \\
\hline EOc & 6.95 & 52.91 & EOc & 9.63 & 41.81 & EOc & 10.88 & 39.11 \\
\hline OKb & 7.63 & 53.32 & OKb & 10.62 & 44.21 & KOb & 8.37 & 39.59 \\
\hline OOd & 4.80 & 59.56 & EKb & 12.20 & 47.85 & OKb & 12.16 & 41.85 \\
\hline OOc & 5.08 & 61.10 & OOd & 6.47 & 57.51 & KKa & 0.36 & 58.47 \\
\hline KOc & 3.81 & 62.68 & KKa & 0.40 & 57.88 & OOd & 7.30 & 58.80 \\
\hline KKa & 0.37 & 64.37 & OOc & 6.79 & 59.94 & OOc & 7.59 & 61.54 \\
\hline $\mathbf{E K b}$ & 8.35 & 70.28 & KOc & 4.78 & 59.98 & KOc & 5.18 & 62.50 \\
\hline OKc & 6.06 & 72.75 & OKc & 8.09 & 64.29 & OKc & 9.17 & 63.09 \\
\hline KKb & 2.68 & 74.93 & $\mathbf{K K b}$ & 3.01 & 71.57 & KKb & 3.24 & 74.96 \\
\hline
\end{tabular}

a Solvent

${ }^{\mathrm{b}}$ Dipole moment of the solvent

c Dipole moment of the tautomer/rotamer

d Percentage of the component is always given in parentheses

e Absolute energy: -954.3782756 a.u.

f Absolute energy: -954.3937370 a.u.

g Absolute energy: -954.4022688 a.u.

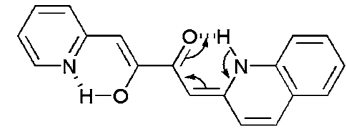

OEa

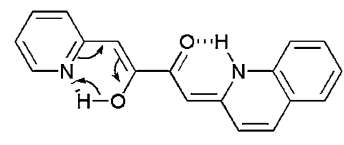

OEa

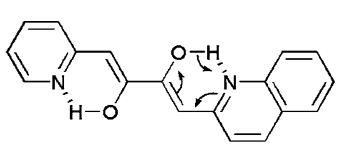

ooa

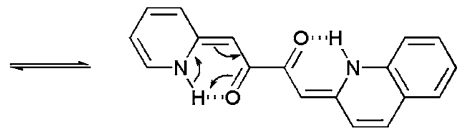

EEa

Scheme 2 Intramolecular proton transfer in OEa

intramolecular hydrogen bonds. There are two such interactions in each molecule of two most stable tautomers. Since all of them are relatively short, their stabilizing effect is evident. Geometry optimization shows that the tautomers studied are planar. Calculations show that length of the H5 $\cdots \mathrm{N} 1$ hydrogen bond in OEa decreases when the solvent became more polar (it is longest in vacuum). On other hand, length of the H5-O5 bond changes in the reverse order (Table 2). Thus, high polarity of the solvent favors shifting of the $\mathrm{H} 5$ proton toward N1 that finally results in transformation of enolimine into enaminone (Scheme 2). This is in agreement with results of the calculations (Table 1) that show percentage of OEa to be lowest in DMSO. 
Table 2 Selected calculated (B3LYP/6-31+G(d,p)) interatomic distances $(\AA)$ and dihedral angles $\left({ }^{\circ}\right)$ in the preferred tautomers of 1-(pyridin-2-yl)-4-(quinolin-2-yl)butane-2,3-dione

\begin{tabular}{|c|c|c|c|c|c|c|}
\hline & \multicolumn{2}{|c|}{ Vacuum $^{\mathrm{a}}$} & \multicolumn{2}{|c|}{ Chloroform $^{\mathrm{a}}$} & \multicolumn{2}{|c|}{$\mathrm{DMSO}^{\mathrm{a}}$} \\
\hline & OEa & OOa & OEa & EEa & EEa & OEa \\
\hline $\mathrm{H} 1 \cdots \mathrm{O} 5 / \mathrm{H} 5 \cdots \mathrm{N} 1$ & 1.709 & 1.698 & 1.685 & 1.747 & 1.780 & 1.674 \\
\hline $\mathrm{H} 1^{\prime} \cdots \mathrm{O} 5^{\prime} / \mathrm{H} 5^{\prime} \cdots \mathrm{N} 1^{\prime}$ & 1.739 & 1.673 & 1.779 & 1.790 & 1.805 & 1.797 \\
\hline N1-H1/H5-O5 & 1.003 & 1.004 & 1.007 & 1.038 & 1.035 & 1.010 \\
\hline $\mathrm{N} 1^{\prime}-\mathrm{H} 1^{\prime} / \mathrm{H} 5^{\prime}-\mathrm{O} 5^{\prime}$ & 1.036 & 1.008 & 1.033 & 1.032 & 1.031 & 1.031 \\
\hline 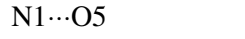 & 2.612 & 2.605 & 2.599 & 2.620 & 2.640 & 2.592 \\
\hline $\mathrm{N} 1^{\prime} \cdots \mathrm{O} 5^{\prime}$ & 2.610 & 2.588 & 2.636 & 2.644 & 2.654 & 2.648 \\
\hline $\mathrm{C} 4-\mathrm{O} 5$ & 1.345 & 1.345 & 1.350 & 1.276 & 1.279 & 1.352 \\
\hline $\mathrm{C} 4^{\prime}-\mathrm{O} 5^{\prime}$ & 1.264 & 1.342 & 1.271 & 1.270 & 1.274 & 1.275 \\
\hline
\end{tabular}

a Solvent

Table 3 Values of HOMA (B3LYP/6-31+G(d,p)) for the preferred tautomers of 1-(pyridin-2-yl)-4-(quinolin-2-yl)butane-2,3-dione in the gas phase and in solutions

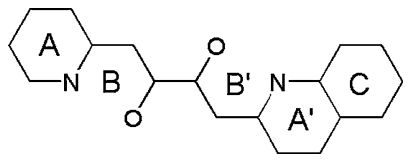

Tautomer Ring A Ring A' Quasi-ring B Quasi-ring B' Ring C $^{\prime}$

\begin{tabular}{cccccc}
\hline Vacuum & & & & & \\
OEa & 0.95 & 0.64 & 0.47 & 0.88 & 0.90 \\
OOa & 0.95 & 0.75 & 0.48 & 0.54 & 0.80 \\
$\mathrm{CH}_{3} \mathrm{Cl}$ & & & & & \\
OEa & 0.96 & 0.67 & 0.41 & 0.91 & 0.89 \\
EEa & 0.84 & 0.66 & 0.90 & 0.91 & 0.90 \\
DMSO & & & & & \\
EEa & 0.85 & 0.67 & 0.89 & 0.91 & 0.89 \\
OEa & 0.95 & 0.68 & 0.38 & 0.91 & 0.89 \\
\hline
\end{tabular}

Except intramolecular hydrogen bonds, aromaticity of the compound is another criterion of its stability [15]. The bond lengths in the tautomeric forms can be used to estimate the geometry-based aromaticity index Harmonic Oscillator Model of Aromaticity (HOMA) [16, 17] defined as
$\mathrm{HOMA}=1-\frac{1}{n} \sum_{j=1}^{n} \alpha_{i}\left(R_{\mathrm{opt}, i}-R_{j}\right)^{2}$

where $n$ represents the total number of bonds in the molecule, $\alpha_{i}$ is a normalization constant (for CC, $\mathrm{CO}$, and $\mathrm{CN}$ bonds $\alpha_{\mathrm{CC}}=257.7, \alpha_{\mathrm{CO}}=157.38$, and $\alpha_{\mathrm{CN}}=93.52$, respectively). It is fixed to give HOMA $=0$ for a model non-aromatic system, e.g., Kekul'e structure of benzene and HOMA $=1$ for the system with all bonds equal to the optimal value $R_{\mathrm{opt}, i}$, assumed to be realized for fully aromatic systems. For $\mathrm{C}-\mathrm{C}$ bonds, $R_{\mathrm{opt}, \mathrm{C}-\mathrm{C}}=138.8 \mathrm{pm}$, for $\mathrm{CN}$ bonds $R_{\mathrm{opt}, \mathrm{C}-\mathrm{N}}=133.4 \mathrm{pm}$ and for $\mathrm{C}-\mathrm{O}$ is $R_{\mathrm{opt}, \mathrm{C}-\mathrm{O}}=126.5 \mathrm{pm}$. The higher the HOMA value, the more aromatic is the ring in question, and hence, more delocalized the $\pi$ electrons of the system.

The calculated values of the index HOMA are presented in Table 3. It is noteworthy that the HOMA values show that (quasi)rings $\mathrm{B}^{\prime}, \mathrm{A}^{\prime}$, and $\mathrm{C}$ in OEa follow the topological phenanthrene-like motif $[18,19]$ with the empty inner ring $\mathrm{A}^{\prime}$, fully aromatic outer quasi-ring $\mathrm{B}^{\prime}$ and ring C. On the other hand, the same rings in OOa tautomer follow the naphthalene-like motif (Scheme 3). The same arrangement of the A and B rings can be seen in the EEa form. Ring A is fully aromatic both in the OEa and OOa molecules. Relatively high HOMA values for the quasirings $\mathrm{B}^{(/)}$prove that intramolecular hydrogen bonds in OEa, OOa, and EEa are of Resonance-Assisted Hydrogen Bond (RAHB) type [20-23].

\section{Conclusions}

Results of the DFT calculations show that (1Z,3Z)-3hydroxy-4-(pyridin-2-yl)-1-(quinolin-2(1H)-ylidene)but-3en-2-one and (1Z,3Z)-1-(pyridin-2-yl)-4-(quinolin-2-yl) buta-1,3-diene-2,3-diol in vacuum are more stable than their other tautomers. Relatively strong intramolecular hydrogen bonds and aromatic character of their molecules is responsible for stability of these species. Basic solvent such as DMSO disfavors the enolimine tautomers. On the other hand, the solute-solvent interactions of the hydrogen
Scheme 3 Graphical illustration of Clar rule for the studied tautomers
OEa

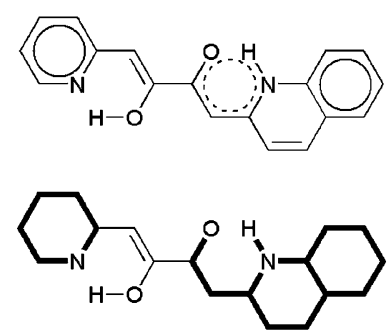

OOa
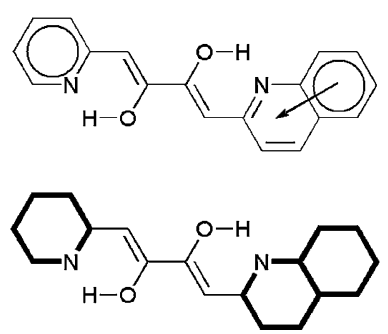

EEa
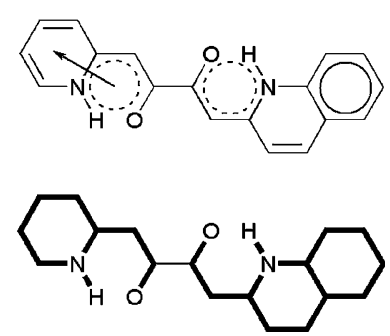
bond character can result in increasing of the contribution of enaminone tautomers in solution.

Acknowledgments We are very much indebted to the ACK CYFRONET AGH, Kraków (MNiSW/SGI3700/UTPBydg/042/2007) and CI TASK Gdańsk for supply of computer time and providing programs.

Open Access This article is distributed under the terms of the Creative Commons Attribution Noncommercial License which permits any noncommercial use, distribution, and reproduction in any medium, provided the original author(s) and source are credited.

\section{References}

1. Katritzky AR (1965) Chem Ind (London) 331-335

2. Kolehmainen E, Ośmiałowski B, Krygowski TM, Kauppinen R, Nissinen M, Gawinecki R (2000) J Chem Soc Perkin Trans 2: 1259-1266

3. Konno Sh, Shiraiwa M, Yamanaka H (1981) Chem Pharm Bull 29:3554-3560

4. Gnichtel H, Möller B (1981) Liebigs Ann Chem 1751-1759

5. Gawinecki R, Kolehmainen E, Loghmani-Khouzani H, Ośmiałowski B, Lovász T, Rosa P (2006) Eur J Org Chem 2817-2824

6. Ośmiałowski B, Kolehmainen E, Nissinen M, Krygowski TM, Gawinecki R (2002) J Org Chem 67:3339-3345

7. Ośmiałowski B, Kolehmainen E, Gawinecki R (2003) Chem Eur J 9:2710-2716

8. Dobosz R, Gawinecki R (2010) J Mol Struct (Theochem) 940:119-123

9. Dobosz R, Gawinecki R, Kanabaj A (2010) J Mol Struct (Theochem) 949:57-59
10. Frisch MJ, Trucks GW, Schlegel HB, Scuseria GE, Robb MA, Cheeseman JR, Montgomery JA Jr, Vreven T, Kudin KN, Burant JC, Millam JM, Iyengar SS, Tomasi J, Barone V, Mennucci B, Cossi M, Scalmani G, Rega N, Petersson GA, Nakatsuji H, Hada M, Ehara M, Toyota K, Fukuda R, Hasegawa J, Ishida M, Nakajima T, Honda Y, Kitao O, Nakai H, Klene M, Li X, Knox JE, Hratchian HP, Cross JB, Bakken V, Adamo C, Jaramillo J, Gomperts R, Stratmann RE, Yazyev O, Austin AJ, Cammi R, Pomelli C, Ochterski JW, Ayala PY, Morokuma K, Voth GA, Salvador P, Dannenberg JJ, Zakrzewski VG, Dapprich S, Daniels $\mathrm{AD}$, Strain MC, Farkas O, Malick DK, Rabuck AD, Raghavachari K, Foresman JB, Ortiz JV, Cui Q, Baboul AG, Clifford S, Cioslowski J, Stefanov BB, Liu G, Liashenko A, Piskorz P, Komaromi I, Martin RL, Fox DJ, Keith T, Al-Laham MA, Peng CY, Nanayakkara A, Challacombe M, Gill PMW, Johnson B, Chen W, Wong MW, Gonzalez C, Pople JA (2004) Gaussian 03 Revision E01 Inc. Gaussian, Wallingford

11. Becke AD (1993) J Chem Phys 98:1372-1377

12. Lee C, Yang W, Parr RG (1988) Phys Rev B 37:785-789

13. Miertus S, Tomasi J (1982) Chem Phys 65:239-245

14. Miertus S, Scrocco E, Tomasi J (1981) Chem Phys 55:117-129

15. Raczyńska ED, Kosińska W, Ośmiałowski B, Gawinecki R (2005) Chem Rev 105:3561-3612

16. Krygowski TM (1993) J Chem Inf Comput Sci 33:70-78

17. Sobczyk L, Grabowski JS, Krygowski TM (2005) Chem Rev 105:3513-3560

18. Clar E (1964) Polycyclic hydrocarbons, vols 1 and 2. Academic Press, London

19. Clar E (1972) Aromatic sextet. Wiley, London

20. Gilli G, Bellucci F, Ferretti V, Bertolasi V (1989) J Am Chem Soc 111:1023-1028

21. Bertolasi V, Gilli P, Ferretti V, Gilli G (1991) J Am Chem Soc 113:4917-4925

22. Gilli P, Bertolasi V, Ferretti V, Gilli G (1994) J Am Chem Soc 116:909-915

23. Bertolasi V, Gilli P, Ferretti V, Gilli G (1996) Chem Eur J 2:925-934 